\title{
PRACTICAL METHODS FOR LOCATING ABANDONED WELLS IN POPULATED AREAS
}

\author{
G. A. Veloski, R. W. Hammack and R. J. Lynn, National Energy Technology Laboratory, Pittsburgh, \\ Pennsylvania
}

\begin{abstract}
An estimated 12 million wells have been drilled during the 150 years of oil and gas production in the United States. Many old oil and gas fields are now populated areas where the presence of improperly plugged wells may constitute a hazard to residents. Natural gas emissions from wells have forced people from their houses and businesses and have caused explosions that injured or killed people and destroyed property. To mitigate this hazard, wells must be located and properly plugged, a task made more difficult by the presence of houses, businesses, and associated utilities. This paper describes well finding methods conducted by the National Energy Technology Laboratory (NETL) that were effective at two small towns in Wyoming and in a suburb of Pittsburgh, Pennsylvania.
\end{abstract}

\section{Introduction}

The two small towns of Midwest and Edgerton evolved in the wake of the Wyoming oil boom of the early 1900s. Less than a mile apart, they lie within the Salt Creek Oil Field of east-central Wyoming, which until recently has suffered declining production since the 1970s. Howell Petroleum, a wholly owned subsidiary of Anadarko Petroleum has implemented a $\mathrm{CO}_{2}$ flood of this old field as part of an enhanced oil recovery (EOR) project. In the early stages of the $\mathrm{CO}_{2}$ flood it became evident that some wells abandoned under the supervision of the previous leaseholders and those that may have predated accurate recordkeeping, would have to be located and re-abandoned to modern standards. This was especially true of EOR production areas in close proximity to Midwest and Edgerton. Anadarko is fervently committed to ensuring that there would be no communication to the surface between these wells and adjacent production areas, however remote the possibility.

In 2004, NETL approached Anadarko about using the Salt Creek Oilfield as a site to test new airborne and ground-based strategies for locating wells. An airborne magnetic survey was later conducted over the entire Salt Creek Oil field including the town of Midwest and Edgerton using the Fugro Midas II system. Details of this study were presented in these conference proceedings (Hammack et al., 2006). Throughout 2005, NETL had successfully located many unmarked abandoned wells (UAW) prior to the benefit of any airborne magnetic data and those that were not apparent in the airborne survey that followed. These ground based magnetic surveys are the focus of this investigation.

Beginning in 1919, some 650 wells were drilled in Versailles Borough, Pennsylvania, an industrial community southwest of Pittsburgh. Within two years, most residents of Versailles Borough, motivated by the lure of overnight riches, or the prospect of ones neighbor becoming wealthy, had their very own gas well. A geologist sent to the area to map these wells said, "Over 600 wells were drilled in an area that could have been drained by ten" (Johnson, 1929). These low pay wells were in decline within a year after completion. It wasn't long thereafter that most of the wells were abandoned and plugged in a utilitarian fashion. A few residents used the natural gas for home heating for a few more years; eventually, all were abandoned. In the 1940s, steel casing was retrieved to the extent possible during wartime scrap metal drives. After about 1960, gas from the wells invaded some homes and businesses leading to complaints of illness, explosions, condemned properties, and the eviction of 
residents. As part of a temporary solution, active and passive vents were installed in areas having elevated methane concentrations. Steel-cased wells have been located by ground-based electromagnetic (Xia, 2001, 2002a, 2002b) and magnetic surveys (Frischknecht et al., 1985; Baer et al., 1995; Xia et al., 2003; Xia and Williams, 2003). NETL (Sams et al., 2004) have used widely spaced airborne measurements of total magnetic field to locate oil and gas wells. In a previous study reported on in these proceedings (Hammack et al., 2006), NETL evaluated a combination of airborne and ground methods, including airborne magnetometry, using the Fugro Midas II and Exploranium GR820 radiometrics, the ALPIS differential absorption lidar (DIAL) sensor developed by LaSen, Inc., and the LDS portable infrared gaseous hydrocarbon detector developed by Apogee Scientific Inc. Findings from this earlier study described improvements in detection, survey design, and optimization.

Magnetometry has been used extensively for location of steel-cased wells. Very early wells were known to have wood casing, and would therefore exhibit no magnetic signature. Some wells have had their casings pulled to be used elsewhere or for scrap. Still others are known to have only surface casing of variable length and state of corrosion, or may have been cut off a few meters below ground level. The magnetic signatures of these wells would be subdued making it difficult to distinguish them from other ferrous metal infrastructure or debris closer to the sensor. Also, certain orientations of buried ferrous metal debris can give rise to anomalies that may be confused with steel well casing. Therefore, a new detection strategy was needed for wells with no casing or non-magnetic casing.

One strategy for the detection of oil and gas wells is based on the hypothesis that leaking wells may be located by sensing volatile components from sedimentary strata that have migrated to the earth's surface via these pathways. The hypothesis should be valid regardless of whether the casing had been removed as long as the well had penetrated a zone still containing residual light hydrocarbons. Even if the well bore has closed due to collapse or some rudimentary attempt at plugging during abandonment, it could still serve as a conduit. Measuring elevated concentrations of methane and other light hydrocarbons on the surface could indicate the presence of a well and would be supportive when magnetic data alone was inconclusive. The detection strategy is not new; soil gas sampling for light hydrocarbons has been used for many years as an exploration technique to evaluate oil and gas potential (Jones and Drozd, 1983; Richers, 1985; Goth, 1985; Richers et al., 1986; Saenz and Pingitore, 1989; Baum et al., 1997; Jones et al., 2005). Soil gas sampling has been proposed as a method for locating faults (Ciotoli et al., 1999; Fountain and Jacobi, 2000). Further, Armstrong (1973) and Johnston et al. (1973) recommended the use of a portable hydrocarbon analyzer to reveal the exact location of wells because many abandoned wells have measurable methane emissions.

This investigation's purpose is to present our experiences locating unmarked and abandoned oil and gas wells in residential areas employing ground-based magnetometer surveys. In the Midwest and Edgerton, Wyoming study areas, the goal was to locate all UAW so they could be properly abandoned; thereby preventing $\mathrm{CO}_{2}$ used in nearby EOR production areas from migrating to the surface from injected formations. In Versailles Borough, Pennsylvania, the wells were located so that they could be monitored by logging, sampling, and flow measurements as part of the ensuing remediation effort to reduce the likelihood of developing explosive concentrations of methane in homes. Further, this study intends to evaluate the ability of magnetometry used in combination with a portable infrared gaseous hydrocarbon detector to discriminate between potential well casing and other infrastructure. An expected outcome of the study is a simplified approach for locating UAW. At the time of this manuscript, the Versailles Borough work has not been completed. 


\section{Survey Description}

\section{Study Areas}

The study area for the magnetic surveys in Midwest and Edgerton, Wyoming are shown in figure 1. Most surveys were conducted within the town of Midwest and the westernmost part of Edgerton. A few sites were also surveyed along the highway connecting the two towns. Magnetic data was collected over many small areas around and between homes not exceeding 0.2 hectare.

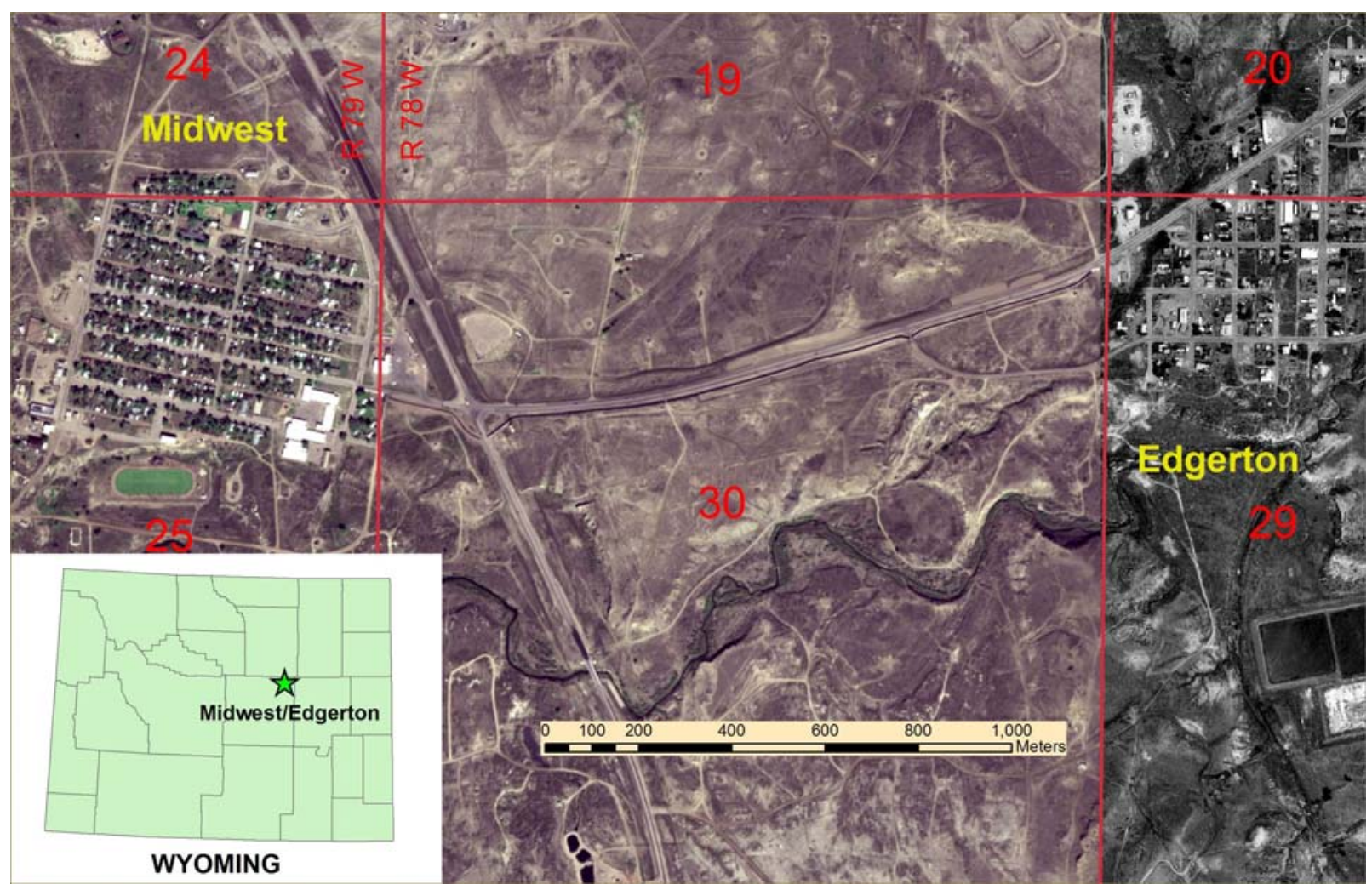

Figure 1. The Midwest and Edgerton study area in east-central Wyoming. The base map was constructed from a mosaic of a USGS 1:12000 digital ortho-quarter quadrangle and a Digital Globe® satellite imagery product.

The Versailles Borough study area (figure 2) is totally within an area of some 20 hectares and may be characterized as a series of closely spaced residential lots. The average lot size that could be traversed with a magnetometer or that was navigable using the cart mounted Apogee was only about 200 $\mathrm{m}^{2}$. A total of approximately 22 line $\mathrm{km}$ of magnetic data and 12 line $\mathrm{km}$ of Apogee LDS methane and light hydrocarbon measurements were collected. The historical photograph in figure 3 underscores the extremely high well density in Versailles Borough. 


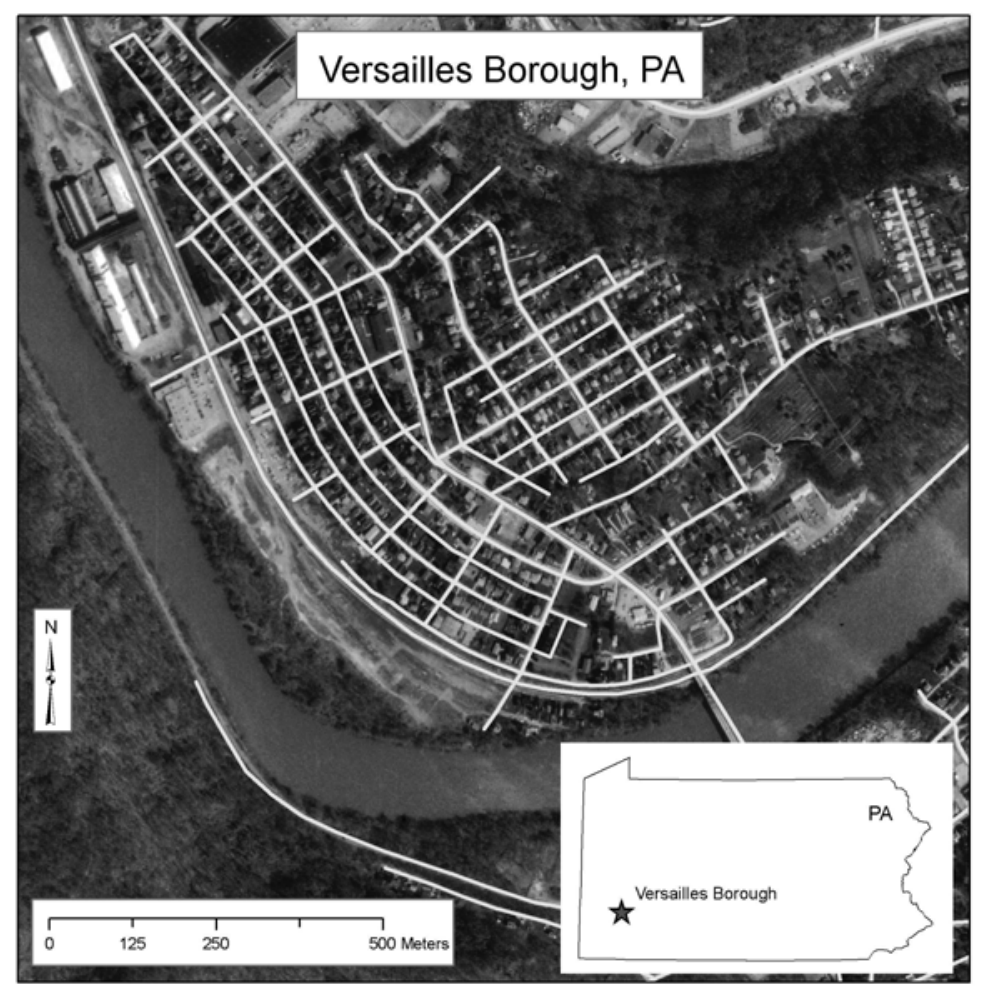

Figure 2. Versailles Borough, Pennsylvania study area along the Youghiogheny River.

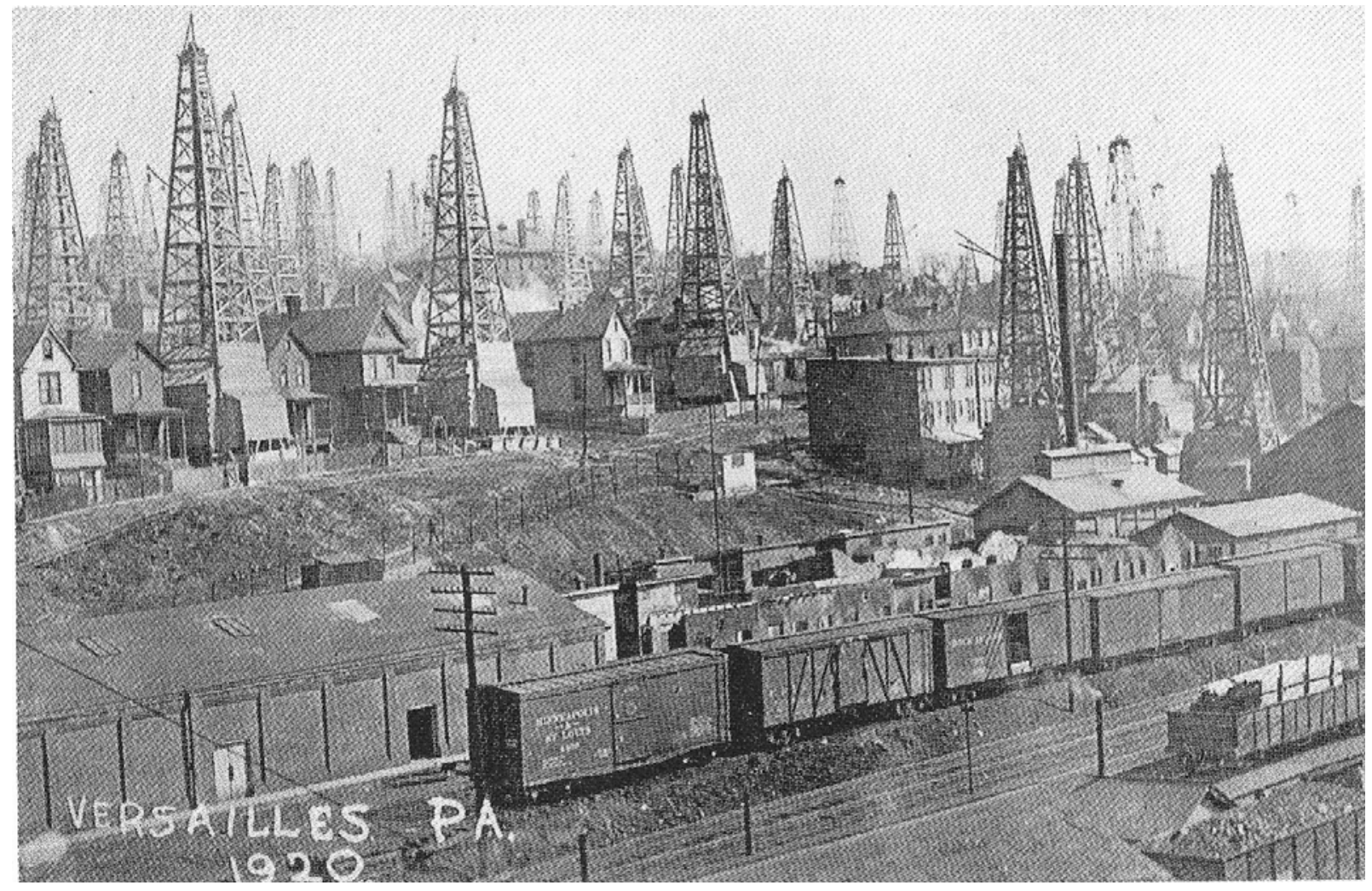

Figure 3. A 1920 photograph of Versailles Borough, PA facing southeast. 


\section{Technical approach}

Data was collected using a Geometrics G-858 cesium ion magnetometer. The magnetometer was operated in continuous collection mode at $10 \mathrm{~Hz}$ using a single sensor. The geomagnetic field for the average location of the surveys was $55170 \mathrm{nT}$ and $53600 \mathrm{nT}$ for the Wyoming sites and Versailles Borough, PA. The amplitudes of the suspected well anomalies were usually in excess of $2000 \mathrm{nT}$ and sometimes as high as $30000 \mathrm{nT}$. Individual surveys were also short in duration ( $<1$ hour). Therefore for our task it was not considered necessary to compensate for diurnal variation of the Earth's magnetic field. Position information was acquired alongside the magnetometer employing a Trimble AG132 global positioning system (GPS) with a multi-path resistant antenna and operated in differential mode augmented by OmniSTAR ${ }^{\circledR}$ supplemental differential correction service for increased accuracy. In this configuration, position data was acquired at $1 \mathrm{~Hz}$ and +/- 0.9 m RMS accuracy

Surveys were conducted on individual lots in Versailles Borough, Pennsylvania by walking a serpentine course in a direction parallel to the longest dimension of each property. A priority was given to surveying the largest contiguous area within the lot that permitted the most unobstructed path. In some lots, the largest contiguous survey area would not allow the collection of more than 3 adjacent parallel swaths; either single line profiles were collected, or the instrument was operated in search mode, in which case no data was logged. Search mode was also used to both target and more precisely determine the position of anomalies discovered during a regular serpentine survey. This was accomplished by observing the magnitude of the digital total field readout in conjunction with the strip chart graphic display on the instrument consol while sweeping a small area with the magnetometer sensor above the target at a constant height. Also, as was often the case in some situations, the GPS fix was lost due to poor reception between dwellings where line of sight could not be established between the GPS antenna and the satellites. It was also possible to experience an intermittent loss of the differential fix, making position data less accurate.

The methane and light hydrocarbon instrument used in Versailles was an Apogee Scientific leak detection system (LDS). The LDS works on the principle of infrared absorption. The LDS is tuned to monitor an absorbance wavelength specific to methane $\left(\mathrm{CH}_{4}\right)$, but will also simultaneously monitor for other light hydrocarbons and $\mathrm{CO}_{2}$. The collective response of the higher molecular weight hydrocarbons $\left(\mathrm{C}_{2}-\mathrm{C}_{6}\right)$ is referred to as total hydrocarbons $(\mathrm{HC})$. The instrument is capable of measuring these species in near real time and at low detection limits ( $0.2 \mathrm{ppm}$, parts per million). The great sensitivity can be attributed to a long effective path length by utilizing a highly folded design. The LDS is also very responsive to changes in analyte concentration due to an active high flow rate induction system. The data system consists of a ruggedized laptop with a wireless interface to the instrument. Data is collected continuously and displayed as three stacked strip charts (one for each analyte channel) displaying concentrations in ppm along with the current location on a moving map presentation. The methane data channel is also linked to an audible indicator that produces pitch changes in proportion to concentration. An input channel for GPS receiver data operated in the differential mode using wide area augmentation system (WAAS) provides accurate position information. The LDS also allows the user to set a threshold above which measured concentrations of methane are automatically logged along with a graphic representation of the peak profile, centered on the maximum concentration. The leaks are enumerated sequentially, and the GPS position of each is reverse geocoded to provide a street address. 


\section{Results and Discussion}

\section{Midwest and Edgerton magnetic surveys}

Accurate databases containing well locations in and around Midwest and Edgerton were available from Anadarko for the wells currently in production, as well as those recently abandoned. There were also database entries available from the Wyoming Oil and Gas Conservation Commission (WOGCC) containing location data in latitude/longitude (decimal degrees) and distances from section boundaries. Wells in the Salt Creek Oil Field were laid out in a boustrophedon fashion similar to the public land survey system of numbering sections in a township. Ideally, there are 36 wells in each quarter section, spaced at approximately $440 \mathrm{ft}$ intervals. In open country, this nominal layout will provide a general area to search for a particular well within a quarter section. Unfortunately, in Midwest, there was a lesser degree of adherence to the normal well pattern. To complicate matters further, there were replicate entries, position errors, undefined datums, numbering errors, and other ambiguities in the WOGCC database.

Several of the wells were originally fitted with P\&A (plugged and abandoned) markers, consisting of a 4 in. vertical steel pipe and identification placards mounted several feet above the ground. For unknown reasons, these were cut off, and normal human activities resumed, sometimes directly over top of the wells. Some were abandoned as recently as 1985, and yet residents living directly across the street from a well for decades could not reliably recollect its location. More reliable are accounts from oil field workers or those who maintained drilling equipment.

Early in the investigation, NETL succeeded in locating 2 UAWs with a magnetometer in Midwest. Figure 4 shows one example. These wells were easy to find because they were located in the only empty lots containing few ferrous metal objects. Thereafter, it became more difficult to discriminate between potential well anomalies and those caused by buried scrap metal, and junked automobiles, partly due to our inexperience. Systematically surveying every confined lot in town and excavation of every target was not an option. The inconvenience and potential property damage would strain already tenuous landowner relations and add to the public's perception of distrust. We therefore had to find a way to increase the probability that a target was a well before excavation. It was apparent that an entirely different strategy would have to be developed or the project would have to be abandoned. 


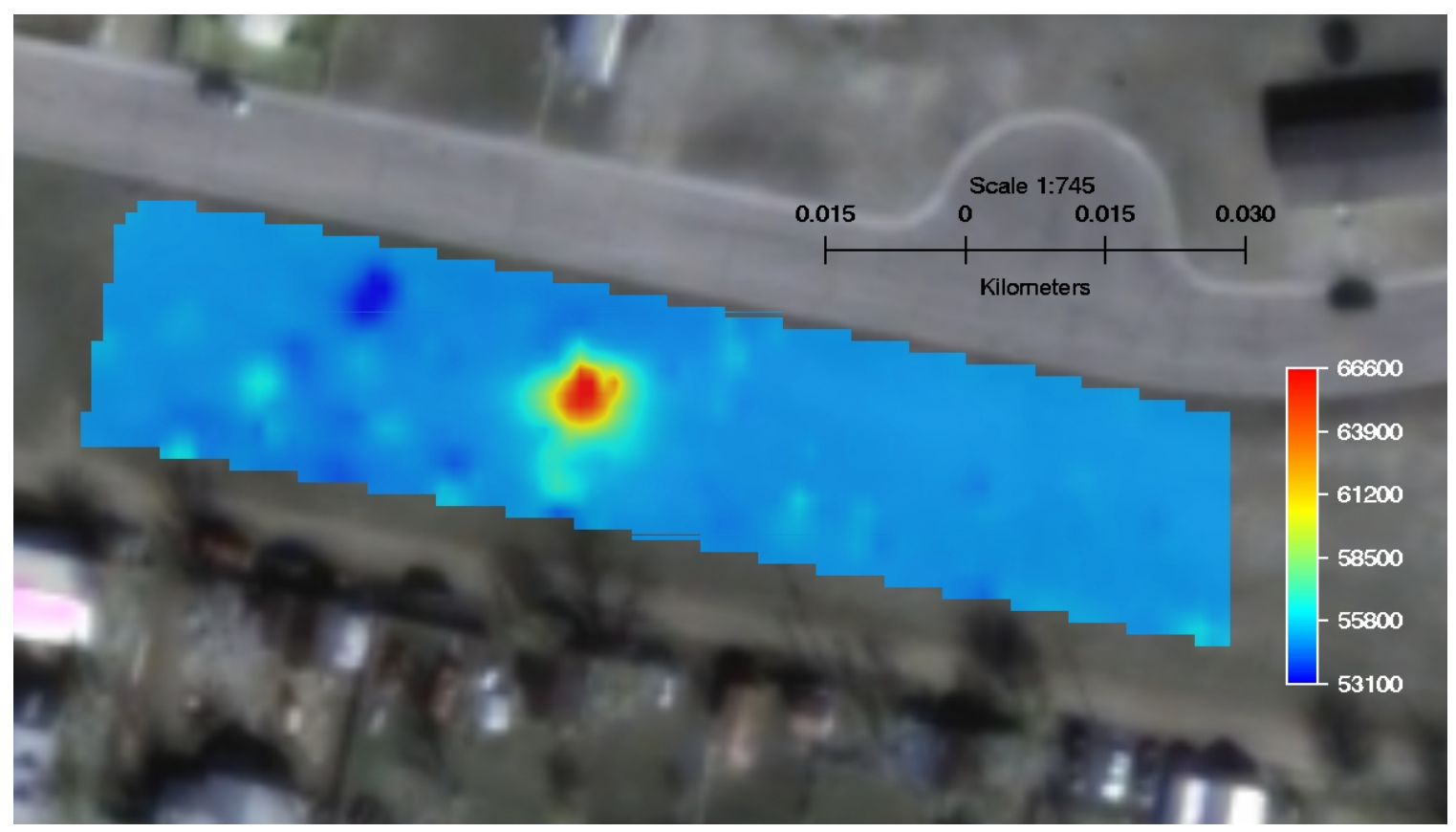

Figure 4. Total field magnetic data from a survey conducted in Midwest was overlaid on a $0.6 \mathrm{~m}$ panchromatic/2.4 m RGB composite satellite image (Digital Globe ${ }^{\circledR}$ ). The strong anomaly near the center of the grid was a UAW about $1 \mathrm{~m}$ below the surface. The Z-scale color bar units are in nanoteslas.

A background site investigation was conducted consistent with that suggested by Jordan and Hare (2002). A visit to the Salt Creek Museum in Midwest proved the best starting point. The museum contained a wealth of information such as historical photographs, maps, air photos, and journal accounts that provided invaluable clues about potential wells. NETL acquired a historic air photo taken in 1930 over the town of Midwest from Salt Creek Museum Curator (figure 5). Although the air photo in of itself was a good resource; it became more valuable when its potential conversion to a map was realized. The air photo was scanned into digital media, and although taken from an oblique perspective, standard image processing techniques could still be used to convert a subset of the image into a pseudoorthographic representation. Known reference locations for which GPS coordinates were earlier collected, served as ground control points for generating an image map projected in real world coordinates. This crude form of polynomial rectification is often referred to by the vernacular "rubber sheeting”. Geographical coordinates extracted in the GIS from the crudely geo-referenced historical air photo agreed well with the approximate locations depicted on other resources including a 1926 USGS cloth map also found at the museum. The air photo map ultimately served well as a geo-referenced image underlay that was loaded as a layer in a GIS running on a PDA, and linked to a GPS receiver. The resulting GPS-linked moving map provided navigation to the area where to begin searching using the magnetometer. This map contributed to the successful excavation of 8 wells in Midwest. Four examples are shown in figure 6. 


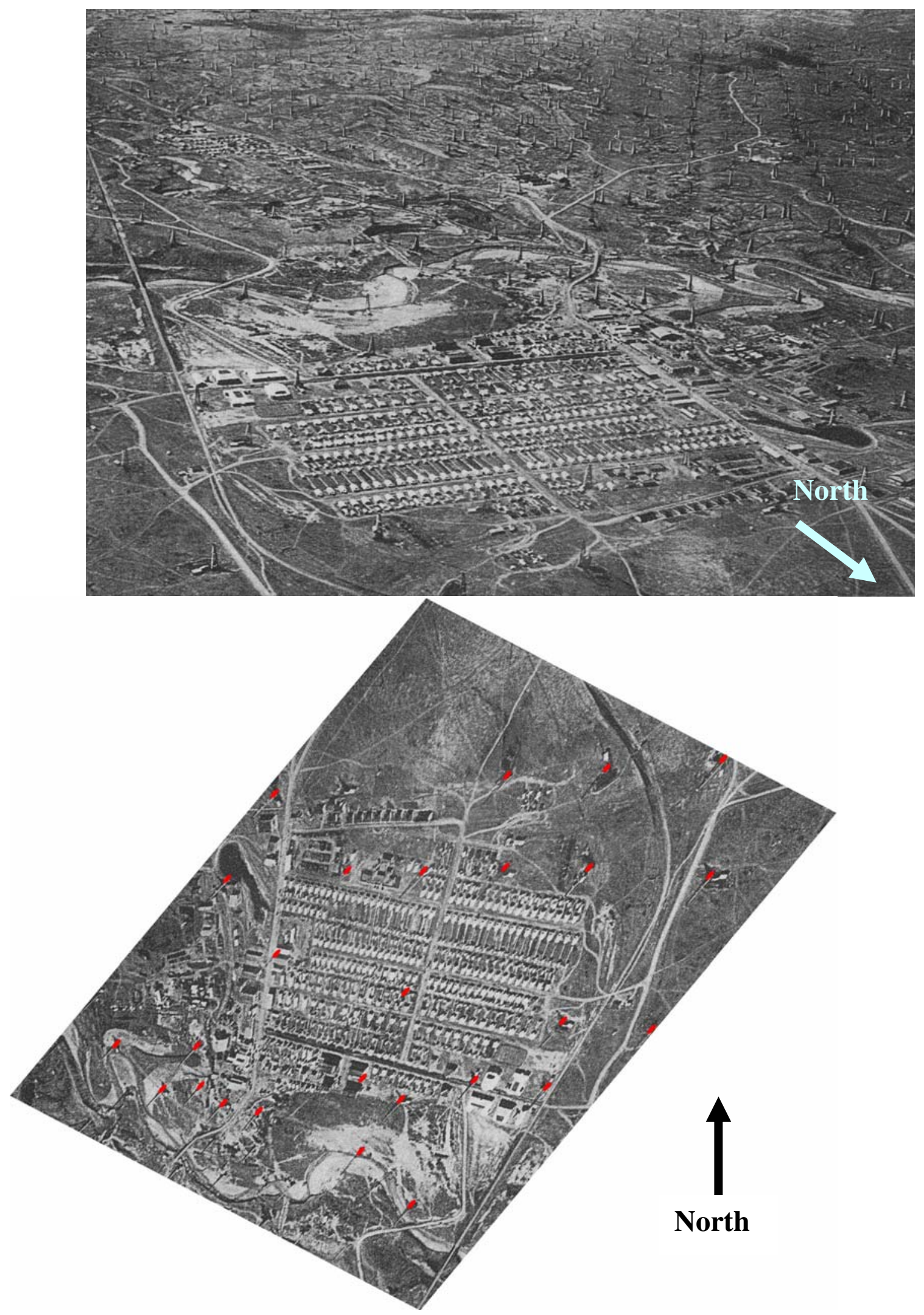

Figure 5. The upper air photo was taken of Midwest in 1930 looking toward the south southwest. The lower image is a subset of the same air photo warped to a pseudo-orthographic representation that conforms to map coordinates using ground control points and a polynomial rectification algorithm. Red symbols indicate the approximate location of the base of wood derricks. Distortion of the red symbols from circular to elliptical is an artifact of the image processing. 


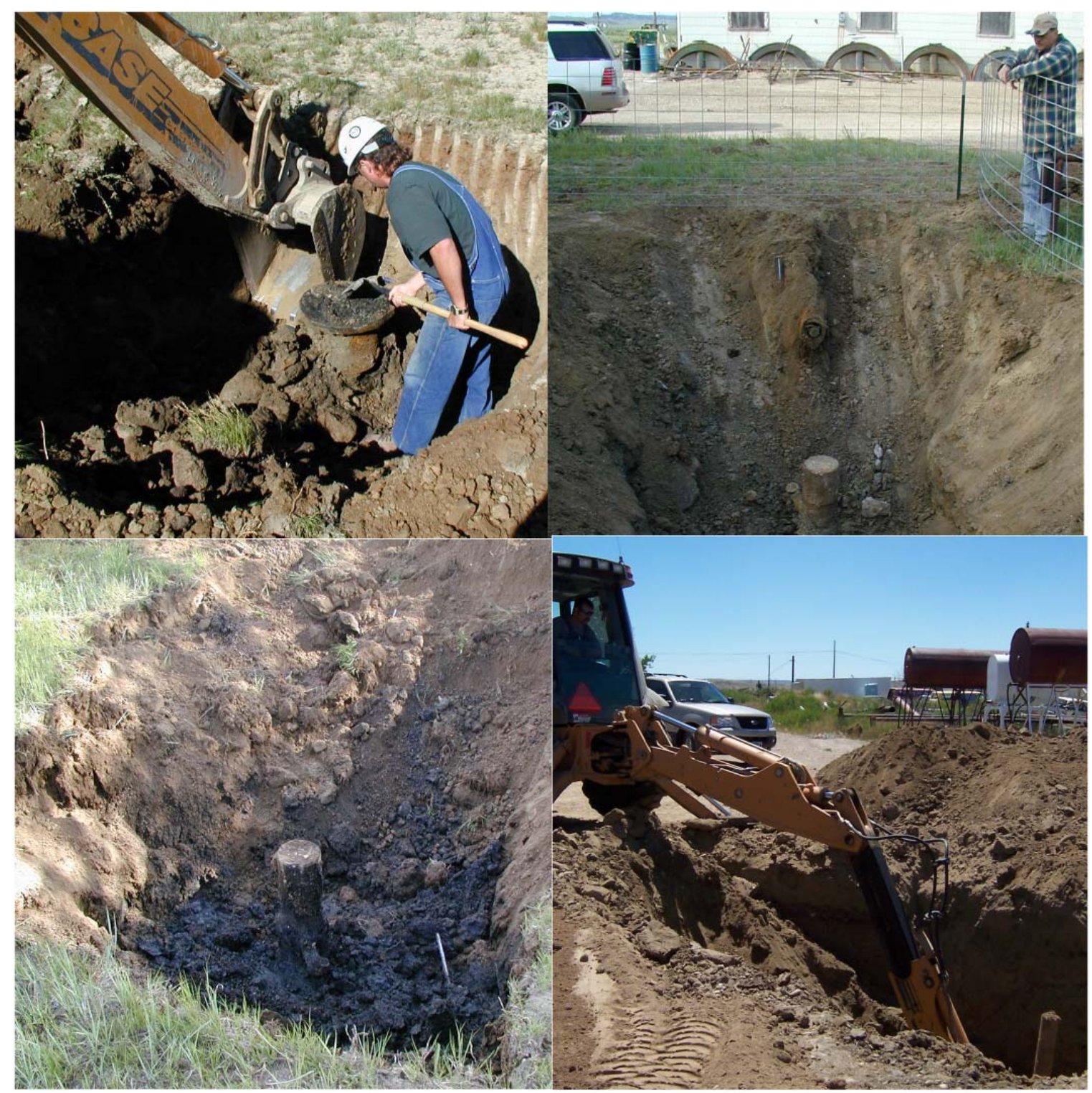

Figure 6. This collage of images shows a few examples of unmarked abandoned wells that were located using GIS and magnetometry then verified by excavation in Midwest, Wyoming.

In a similar case, NETL used a 1920 photograph, DGPS data, and GIS to determine the approximate position for an abandoned well. The upper photograph shown in Figure 7 was taken in 1920 looking south along Fitshugh Street in Midwest. The original utility poles were constructed of spruce, and are easily identified by a large number of knots and a highly furrowed, weathered surface. Local residents also pointed out the old practice of cutting an angle atop the pole to shed water. The lower digital photo shows the position where the alignment of these original poles with the corners of both a hotel and machine shop are consistent with the 1920 photograph. The position for the 1920 photograph and utility poles were then established using DGPS and entered into a GIS. A location from where to search for the well was determined using lines of position. The UAW was found in less than a minute with the magnetometer, only $2 \mathrm{~m}$ from the narrowed search location. Excavation uncovered the 12 in. diameter well casing only $1 \mathrm{~m}$ deep and plugged with a square block of wood. The well was exuding oily water. 


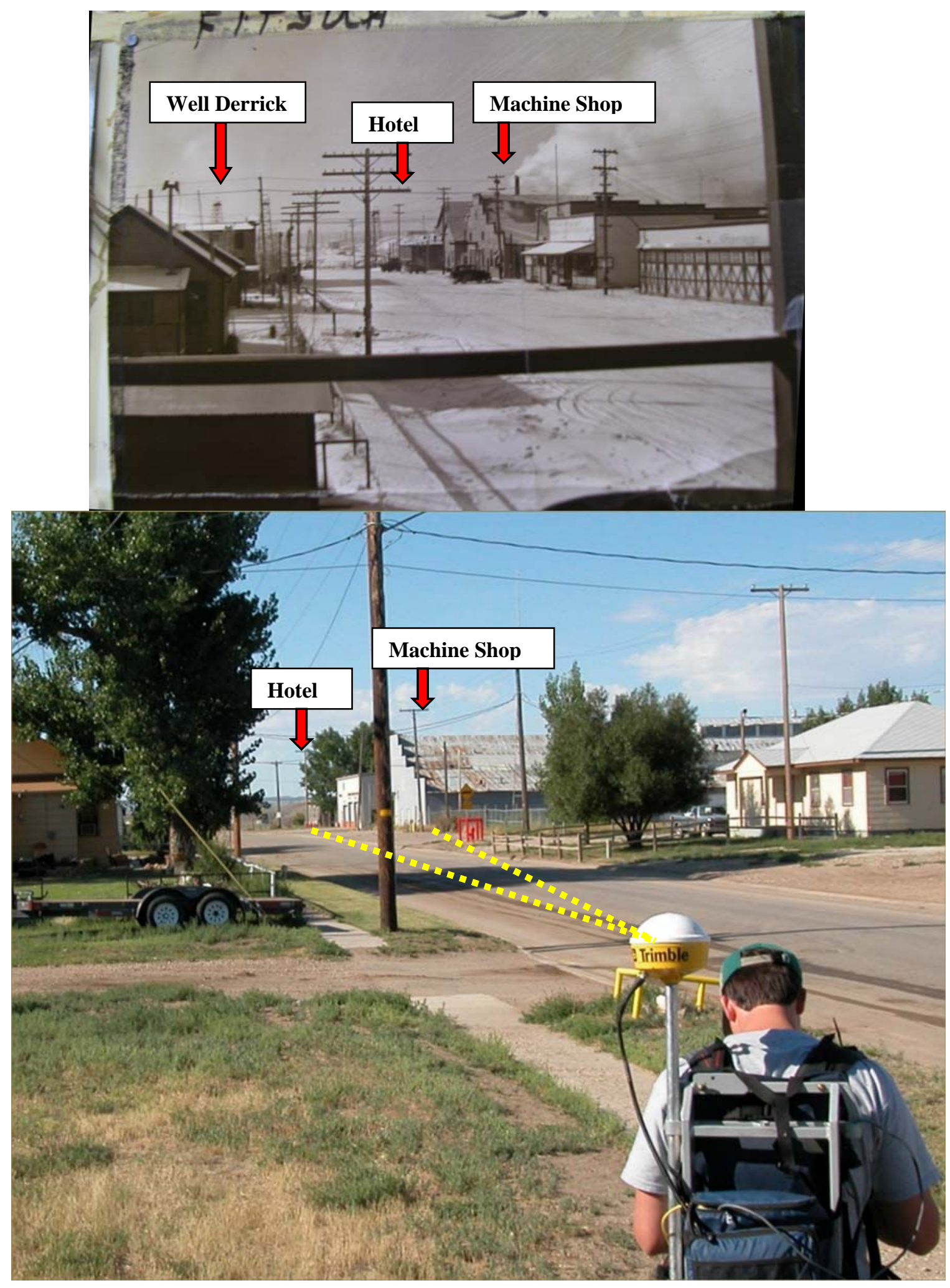

Figure 7. The upper photograph was taken in 1920 looking toward the south along Fitshugh Street in Midwest. The lower image was taken from the same location as the 1920 photo as determined by the alignment of features common to both images. DGPS measurements and lines of position were used to find the unmarked abandoned well from distance measurements in a GIS. 
DGPS coordinates collected at the aforementioned recovered wellheads, were used in turn to refine other UAW positions depicted on other historical maps. These bootstrap procedures ultimately lead to the location of 23 UAW in the study area. Of the 25 excavations performed, 23 wells were located with a horizontal accuracy of less than a single backhoe bucket width $(0.6 \mathrm{~m})$. One excavation missed the well by $2 \mathrm{~m}$, probably owing to a broadening of the anomaly because the wellhead was located more than $3 \mathrm{~m}$ below the surface. One target consisted of an 8 in by $12 \mathrm{ft}(0.2 \mathrm{~m}$ by $3.7 \mathrm{~m})$ vertically-oriented and concrete filled steel pipe that served as a derrick anchor. NETL's overall success rate was $96 \%$.

\section{Versailles Borough surveys}

In a manner similar to the surveys conducted in Wyoming, the Versailles Borough investigation was initiated by gathering all available sources of information pertaining to the wells. Historical photographs such as in figure 3 were used to determine an approximate location for certain wells juxtaposed to dwellings and landmarks that may be identified today. NETL also acquired a hand drawn map depicting the approximate locations for many of the wells. This map was scaled and rotated to coregister as closely as possible with a map coordinate system, and well locations were manual extracted by digitization. These data were integrated as layers in a GIS along with modern digital air photos (DOQs), topographical maps and property maps.

NETL commenced the survey effort focusing initially on a location that could serve as a control; a location long suspected by some residents to be a genuine UAW. The site was situated in a small depression and was observed to evolve a light stream of gas bubbles upon wetting the area with a hose. A magnetic survey of the site showed a prominent anomaly that was later excavated and a 10 in by $20 \mathrm{ft}$ $(0.25 \mathrm{~m}$ by $4.5 \mathrm{~m})$ long steel well casing and closed well bore were found. Prior to excavation, the Apogee LDS methane and gaseous light hydrocarbon detector, mounted on a truck, recorded a significant response for methane up to about $20 \mathrm{~m}$ downwind from this well. Significant methane anomalies were defined as greater than 2 standard deviations above average. The observed uncalibrated background methane concentration was about $2 \mathrm{ppm}$.

NETL then decided to conduct a street wide Apogee LDS survey of Versailles Borough from the truck in an effort to target methane plumes that could be traced back to their sources. In an earlier study at the Salt Creek Oil Field, NETL successfully detected and traced numerous methane sources originating from oil well pumping units and a broken gas condensate line. The Versailles Borough methane sources were expected to be leaking UAWs that would then be more accurately located using a magnetometer. The results of the Apogee LDS street survey are shown in figure 8. Several methane anomalies were found, although only a few could be traced back to the sources. The sources were identified as passive vents installed to divert methane. Some of these vents are known to be located atop abandoned gas wells. It may be interesting to note that the highest measured methane concentration (13.6 ppm) in the Apogee LDS street survey was traced to a sanitary sewer vent. Upon close examination of the color-coded concentration profiles derived from the street survey in figure 6, evidence for plumes can be observed. In fact, consecutive surveys performed after a shift in wind direction reveals that certain sources persist for considerable distances. Ideal survey conditions are when the survey direction is upwind and crosswind to the source and don't change for the duration of the survey. It soon became apparent that ideal conditions seldom occur. Wind direction can suddenly change from obstruction induced turbulence along with eddy currents that further complicate interpretation of the methane plumes due to partitioning and dilution. Our method to target potential UAWs using the Apogee LDS would have to be revised in order to distinguish between low volume methane sources and a transient plume intercepted from a nearby vent. The instrument would therefore, have to be brought closer to the source of leaking methane. 


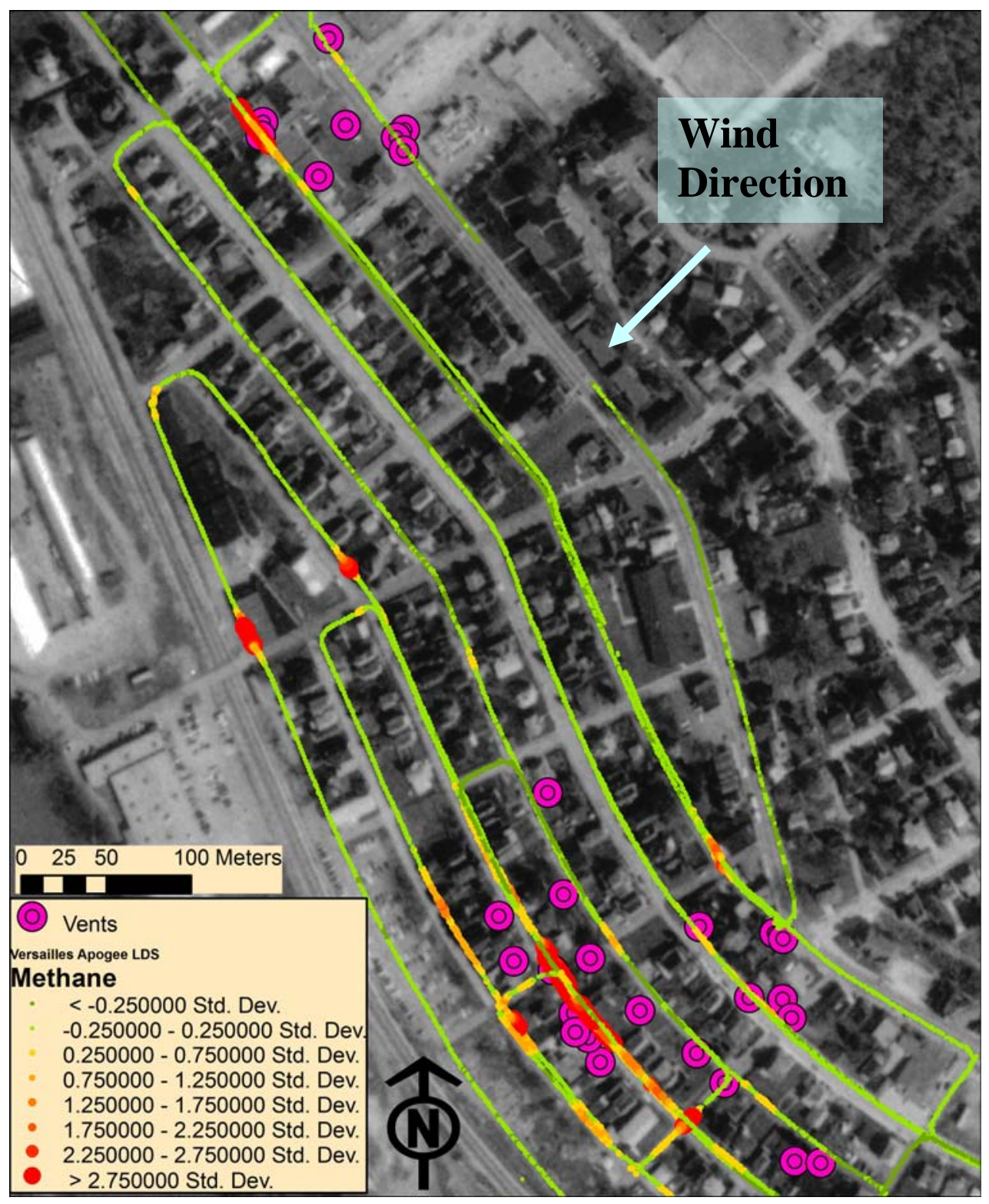

Figure 8. Results from an Apogee LDS survey of Versailles Borough. Methane concentrations along the vehicle GPS track are represented by graduated symbol and color. The magenta symbols are the GPS locations of passive vents. Some vents are associated with abandoned gas wells

The Apogee LDS was mounted in a lightweight folding cart constructed of aluminum (figure 9). The air induction system was modified so that sampling would occur through a pipe mounted about 10 $\mathrm{cm}$ above the ground. To avoid contamination, the sensitive optical elements are protected by two automotive type cylindrical air filter elements mounted in series on the intake side of the induction system. Input from a mass air flow sensor was used to compensate for irregularities in induction rate due to obstructions that could otherwise affect the response.

A systematic survey of all accessible lots in Versailles Borough was then performed over the course of several days using the cart-mounted implementation of the Apogee LDS. Magnetic surveys 


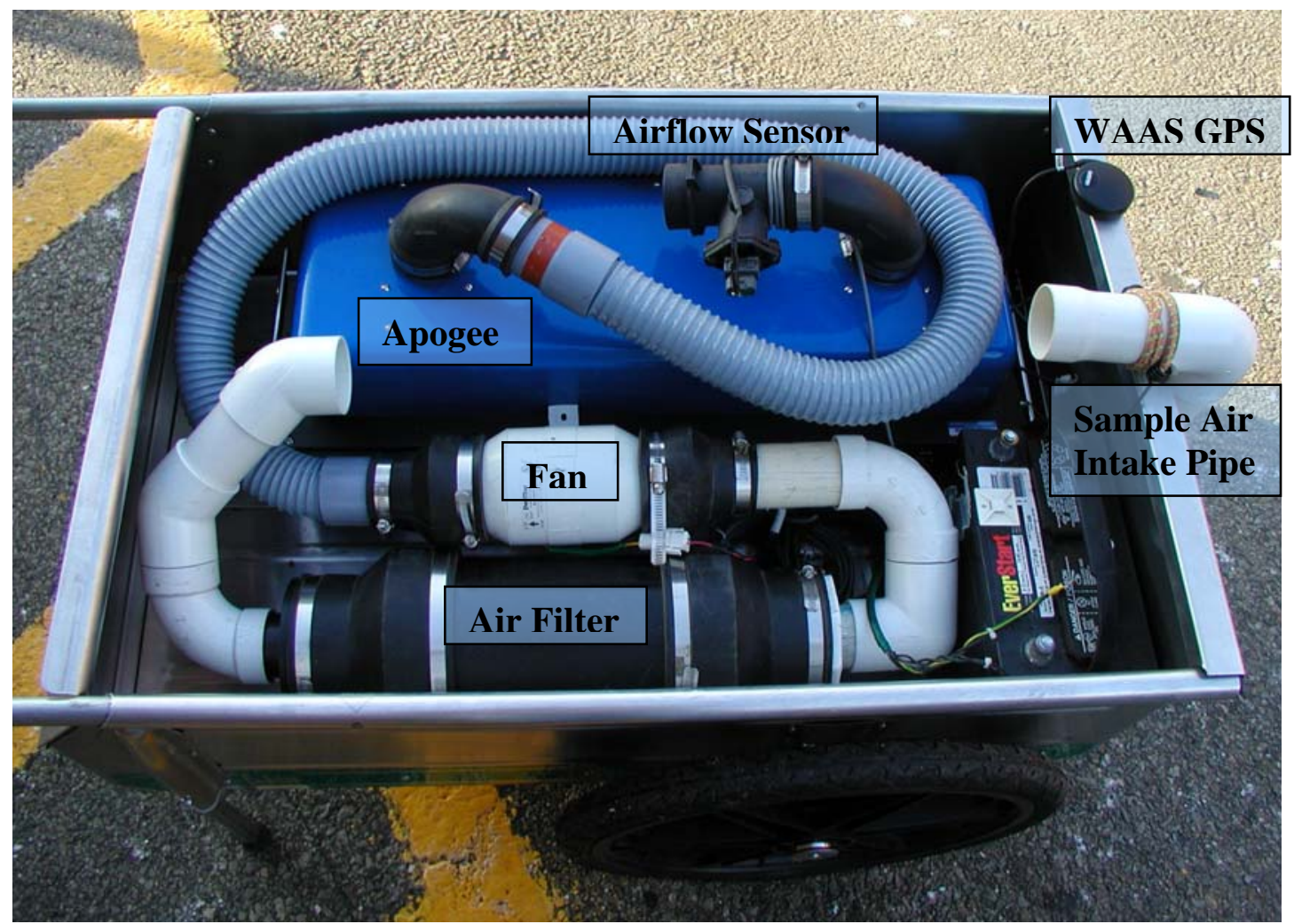

Figure 9. Apogee LDS methane and light hydrocarbon instrument mounted in a lightweight aluminum cart. The intake hose was removed for clarity as was the ruggedized tablet computer data system.

were sometimes conducted in tandem which worked well because the cart left a faint trail that was easily followed. Several methane anomalies were detected and found to be highly localized. Many of these sources showed high concentrations of methane (100-1500 ppm) when sampled close to the ground, but due to the very low flow rates, a rapid dilution effect was observed only 2-3 $\mathrm{m}$ away. This was confirmed when conducting multiple traverses over the same methane source at varying distances. It was possible to pass by a methane source without noting a response when further away than about $2 \mathrm{~m}$. Based upon this observation, the interline spacing for consecutive traverses was reduced to about $2 \mathrm{~m}$ to reduce the likelihood of missing a potential leaking UAW. A sample induction delay of about 3 seconds was also observed. The delayed response causes displacement errors in the data analogous to the parallax error observed in uncorrected GPS-linked magnetometer data. Position error observed with the Apogee LDS increases with traverse rate.

Numerous magnetic surveys were conducted in the residential lots of Versailles Borough (figure 10). The results from the street-wide Apogee LDS survey were used to delineate potential problem areas on which to focus these efforts. So far, 43 very strong monopole-like magnetic anomalies in excess of $5000 \mathrm{nT}$ were detected. However, at the time of this manuscript, data collection has not concluded, and permission has only been obtained to excavate and confirm that one anomaly is indeed a well (figure 11). The cart mounted Apogee LDS instrument measured elevated methane concentrations in close proximity to 7 of 43 strong magnetic anomalies. 


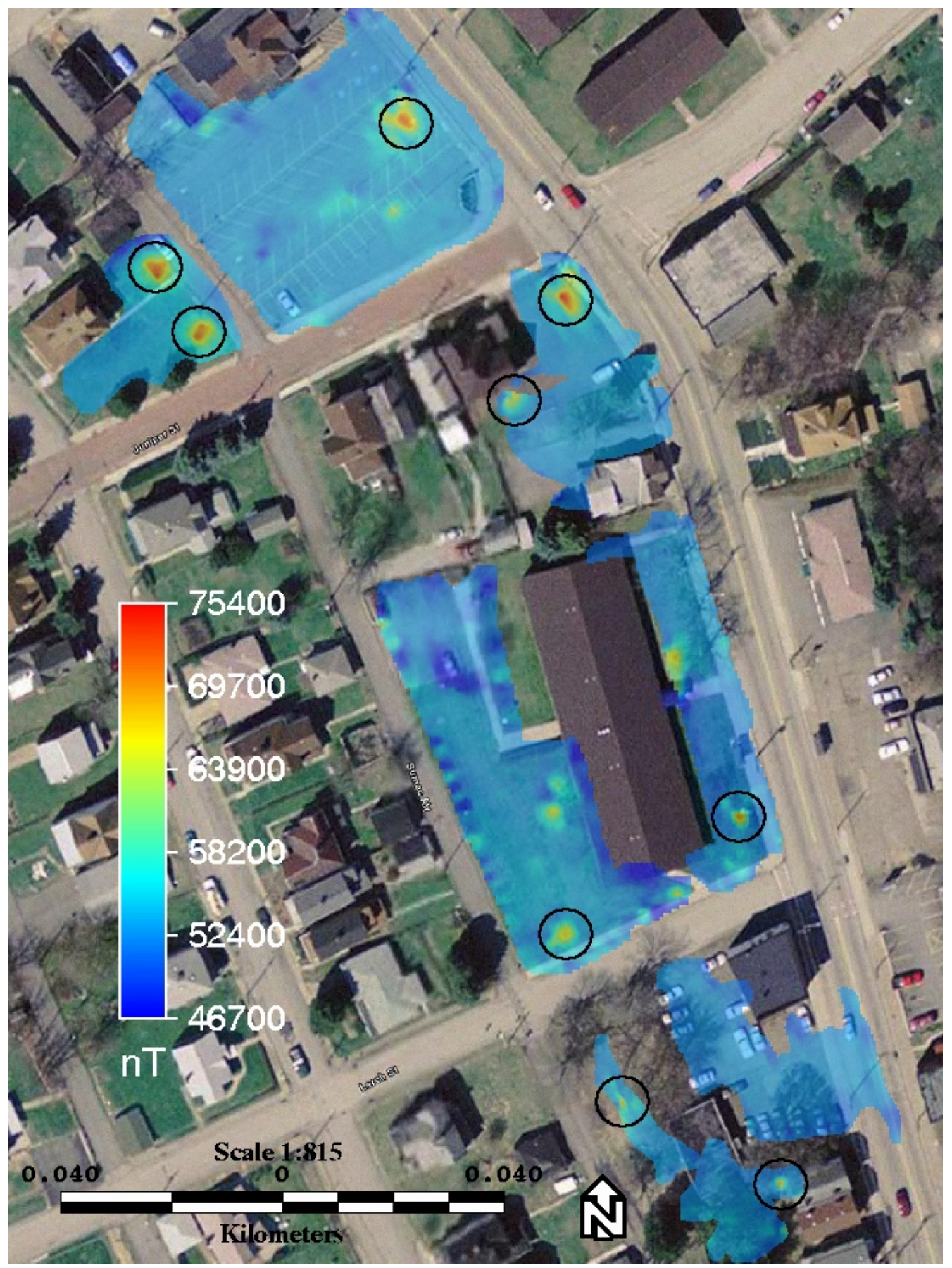

Figure 10. Total field magnetic data collected over a portion of Versailles Borough, PA. Suspected abandoned gas wells are circled. The normalized magnetic data grids are presented as a semitransparent overlay on geo-referenced Google Earth ${ }^{\mathrm{TM}}$ imagery (@2007 Europa Technologies, (C2007 Navteq). 


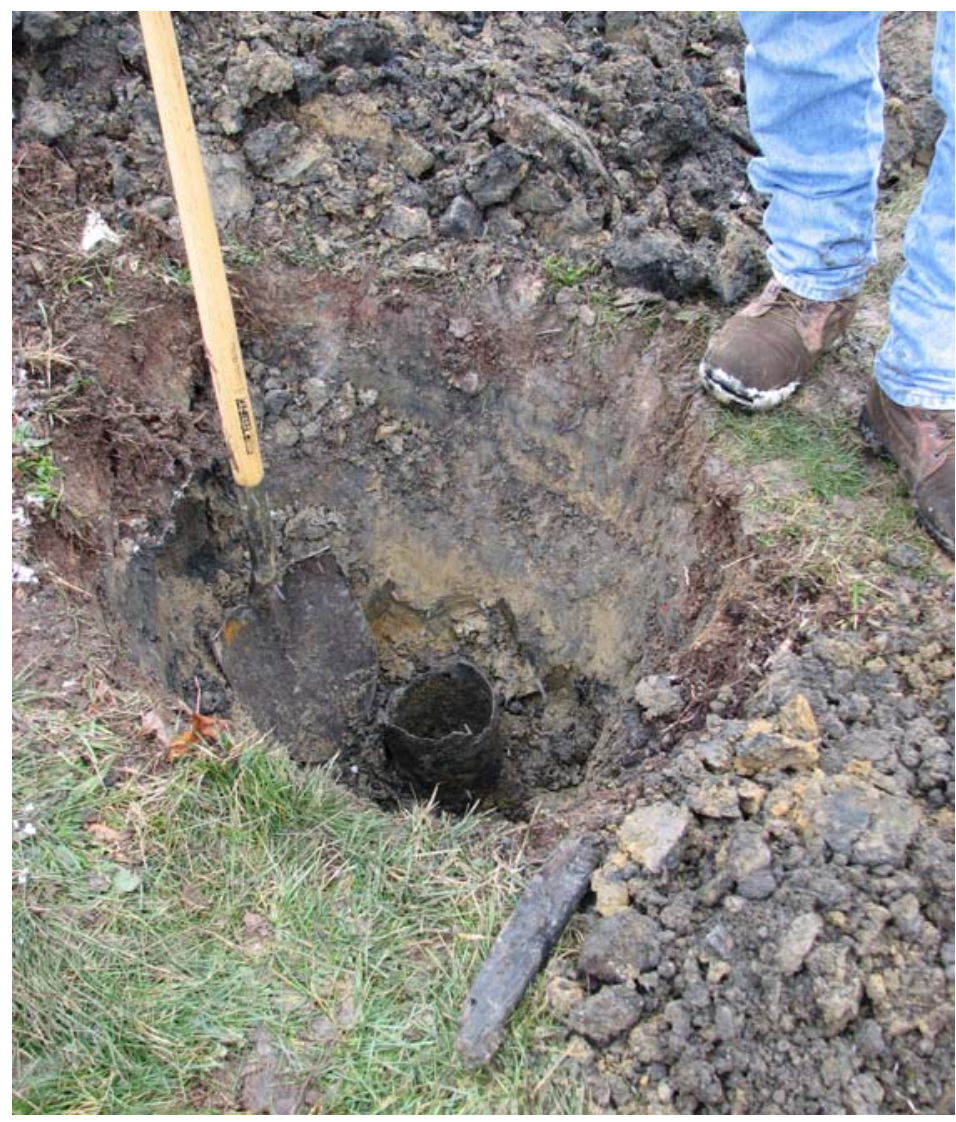

Figure 11. UAW excavated in Versailles Borough, PA. This well was first detected by methane measurements and subsequently by magnetometry

\section{Conclusions}

Magnetic surveys were used successfully to locate unmarked abandoned wells (UAW) in Midwest and Edgerton Wyoming, and to target many potential wells in Versailles Borough Pennsylvania. In Midwest and Edgerton Wyoming, conducting magnetic surveys in residential lots was made more difficult by the presence of buried ferrous metal trash and numerous obstructions. Historical photographs and GPS surveys were extremely advantageous for locating wells when combined with image processing and GIS. Employing these techniques greatly reduced both the area and number of residential lots surveyed using a magnetometer. NETL found 24 UAWs out of 25 excavations, a success rate of $96 \%$. To our knowledge, all wells in Midwest and Edgerton for which any records were found have been located.

At the time of this manuscript, 43 magnetic anomalies were found in Versailles Borough. Although most or all of these anomalies are suspected UAWs, only 1 has been confirmed. 7 of these anomalies were associated with very high methane levels when measured using the Apogee LDS methane and light hydrocarbon detector mounted on a cart and sampling the air close to ground level. The Apogee LDS was shown to be highly sensitive and very effective for targeting areas containing a high density of abandoned gas wells that are leaking simply by driving the streets. Several methane plumes could be traced to their sources, mainly passive gas vents, some of which were mounted on top of abandoned gas wells. 


\section{References}

Aller, L., 1984, Methods for Determining the Locations of Abandoned Wells, EPA-600/2-83-123. Armstrong, F. E., 1973, Locating uncharted oil and gas wells: state-of-the-art: U.S Bureau of Mines Tech. Prog. Rep., TPR 65, 11 p.

Baer, L. J., R. Overfelt, and T. Faile, 1995, Total field magnetic surveys to locate abandoned wells: three case histories: The Leading Edge, V. 14, N. 4, p. 237-241.

Baum, M. G., Karl-Heinz Bleschert, M. Wagner, and M. Schmitt,1997, Application of surface prospecting methods in the Dutch North Sea, Petroleum Geoscience, V.3, pp. 171-181.

Ciotoli, G., G. Etiope, M. Guerra, and S. Lombardi, 1999, The detection of concealed faults in the Ofanto Basin using the correlation between soil-gas fracture surveys, Tectonophysics, V. 301, pp. 321-332.

Fountain, J. C., and R. D. Jacobi, 2000, Detection of buried faults and fractures using soil gas analysis, Environmental and Engineering Geoscience, V. 6, No. 3, pp. 201-208.

Frischknecht, F. C., R. Grette, P. V. Raab, and J. Meredith, 1985, Location of abandoned wells by magnetic surveys; acquisition and interpretation of aeromagnetic data for five test areas: USGS Open-File Report 85-614A, 64 p.

Goth, Michael, 1985, Indication of methane movement from petroleum reservoir to surface, Loningen Oilfield, NW-Germany, Journal of Geochemical Exploration, V. 23, pp. 81-97.

Hammack, R. W., G. A. Veloski, G. Hodges, S. McLaren, and C. M. White, 2006, An Evaluation of Helicopter and Ground Methods for Locating Existing Wells, SAGEEP.

Johnston, K. H., H. B. Carroll, R. J. Heemstra, and F. E. Armstrong, 1973, How to find abandoned oil and gas wells, U.S. Bureau of Mines Information Circular 8578, 36 p. plus appendices.

Jones, V. T. and R. D. Drozd, 1983, Predictions of oil or gas potential by near-surface geochemistry: AAPG Bull., V. 67, No. 6, pp. 932-952.

Jones, V. T., W. Harbert, T. Anderson, and J. Izzo, 2005, GIS-based analysis of light hydrocarbons in soil gases-Lost River region, West Virginia: relation to stratigraphy and geological structures: AAPG Bull., in press.

Jordan, P. W. and J. L. Hare, 2002, Locating Abandoned Wells: A Comprehensive Manual of Methods and Resources, Solution Mining Research Institute, Report No. 2002-1-SMRI.

Otton, J. K., Sigrid Asher-Bolinder, D. E. Owen, and Laurel Hall, 1997. Effects of produced waters at oilfield production sites on the Osage Indian Reservation, northeastern Oklahoma Open File Report 97-28, U.S. Geological Survey.

Richers, D. M., 1985, Some methods of incorporating remote sensing and surface prospecting with hydrocarbon exploration: Assoc. Petrol. Geochem. Explorationists, Special Publication No. 1, June 7, Denver, CO, pp. 11-30.

Richers, D. M., V. T. Jones, M. D. Matthews, J. Maciolek, R. J. Pirkle, and W. C. Sidle, 1986, The 1983 Landsat soil-gas geochemical survey of Patrick Draw area, Sweetwater County, Wyoming, American Association of Petroleum Geologists Bulletin, V. 70, No. 7, pp. 869-887.

Saenz, G., and N. E. Pingitore, Jr., 1989, Surface organic geochemical prospecting for hydrocarbons: multivariate analysis, Journal of Geochemical Exploration, V. 34, pp. 337-349.

Sams III, J. I., R. W. Hammack, G. A. Veloski, T. E. Ackman, M. S. Zellman, B. A. Lipinski, and W. A. Harbert. 2004. Using helicopter electromagnetic surveys to determine the fate of water coproduced with coalbed natural gas in the Powder River Basin, poster, AAPG Annual Meeting, Houston, Texas. 
Southwest Research Institute, 2004, Field testing of remote sensor gas leak detection systems, http://seca.doe.gov/scngo/NaturalGas/publications/t\&d/Final\%20Report_RMOTC.pdf

Van der Meer, Freek, Paul van Dijk, Harald van der Werff, and Yang, Hong, 2002, Remote sensing and petroleum seepage; a review and case study, Terra Nova, V. 14, No. 1, pp. 1-17.

Warner, T. A., 1999. Integration of remotely sensed geobotanical and structural methods for hydrocarbon exploration in a closed canopy forest. In: S. J. Lippard, A. Naess and R. SindingLarsen (Eds.), Proceedings of the IAMG '99, p. 451-456.

Xia, J., 2001, Using electromagnetic method to locate abandoned brine wells in Hutchinson, Kansas: Kansas Geological Survey Open-file Report 2001-17.

Xia, J., 2002a, Using electromagnetic methods to locate abandoned brine wells in Huchinson, Kansas: Symposium on the Application of Geophysics to Engineering and Environmental Problems (SAGEEP) 2002 Annual Meeting of EEGS, Las Vegas, Nevada, February 10-14, 2002, 11pp.

Xia, J., 2002b, Results of electromagnetic survey in Hutchinson, Kansas in May 2001: Kansas Geologic Survey Open-file Report 2002-52, 273 p.

Xia, J., and S. L. Williams, 2003, High-resolution Magnetic Survey in Locating Abandoned Brine Wells in Huchinson, Kansas, Symposium on the Application of Geophysics to Engineering and Environmental Problems (SAGEEP) 2002 Annual Meeting of EEGS, Las Vegas, Nevada, April 6-10, 2003, 12p.

Xia, J., C. Chen, S. Xia, and D. Laflen, 2003, Applications of high-resolution magnetic method and gradient method in locating abandoned brine wells in Hutchinson, Kansas: Kansas Geological Survey Open-file Report 2003-48, 150 p.

\section{Acknowledgements}

The authors wish to thank Anadarko Petroleum for providing access to the Salt Creek Oilfield. We acknowledge the efforts of Midwest Mayor Guy Chapman and employees of Anadarko Petroleum and Howell Petroleum, particularly, Tammy Hitt and Cathy Van Norman. Special thanks to Pauline Schultz, Curator of the Salt Creek Museum in Midwest for providing resources.

\section{Disclaimer}

Brand name products described in this manuscript are intended to facilitate understanding and are not endorsed by the United States Department of Energy 